\title{
A model for the phenotypic plasticity of North sea herring growth in relation to trophic conditions
}

\author{
Yunne-Jai Shin ${ }^{(*)}$, Marie-Joëlle Rochet \\ Laboratoire de mathématiques appliquées à l'exploitation des ressources halieutiques et aquacoles, mue de l'ìle d'Yeu, \\ BP 21105, 44311 Nantes cedex 3, France.
}

Received March 6, 1998; accepted August 27, 1998.

\begin{abstract}
An adaptation of the von Bertalanffy growth model is formulated to describe the phenotypic plasticity of fish somatic growth in relation to trophic conditions. The model is developed for the North sea Downs herring (Clupea harengus). It suggests that annual growth variability during 1974-1990 was mainly due to the combined effects of herring abundance and wind-induced turbulence (coincident with the spring stratification of the water column). Springtime turbulences cause reduced and delayed planktonic blooms preceding the annual foraging period of Downs herring. The negative relation observed between herring abundance and growth is hypothesized to be due to intra-specific competition for trophic resources. Incorporated into the calculation of yield per recruit, the established growth model provides slightly more optimistic diagnoses while dropping the classic assumption of constant weight at age. (1) Ifremer/Elsevier, Paris
\end{abstract}

Growth model / density dependence/ phenotypic plasticity / fishery management / Clupea harengus / North sea herring

Résumé - Un modèle pour la plasticité phénotypique de la croissance du hareng de la mer du Nord en fonction des conditions trophiques. Une adaptation du modèle de croissance de Von Bertalanffy est proposée afin d'exprimer une plasticité phénotypique de la croissance somatique des poissons en fonction des conditions trophiques. Le modèle est développé sur l'exemple du hareng des Downs en mer du Nord (Clupea harengus). Sur la période 1974-1990, l'ajustement du modèle suggère que la variabilité interannuelle de croissance en longueur est principalement due à l'action conjointe de deux facteurs : la croissance est reliée négativement à l'abondance des harengs et à la turbulence due au vent (contemporaine de la stratification printanière de la colonne d'eau). Des turbulences trop importantes sont en effet supposées diminuer et retarder le pic du bloom planctonique précédant la phase annuelle de nutrition des harengs. En outre, la relation négative entre l'abondance des harengs et leur croissance est interprétée comme une conséquence de la compétition intraspécifique pour les ressources trophiques. Des simulations de rendement par recrue à partir du modèle de croissance proposé montrent que la prise en compte d'une croissance dépendant de la densité fournit des diagnostics légèrement plus optimistes. (C) Ifremer/Elsevier, Paris

Modèle de croissance / densité-dépendance / plasticité phénotypique / Clupea harengus / hareng de mer du Nord / gestion des pêches

\section{INTRODUCTION}

Fish population models usually describe individual growth only as a function of age. However, there is growing evidence of growth phenotypic plasticity in fish (e.g. [31, 43, 59]). Phenotypic plasticity is defined as the variability of the phenotypic expression of a genotype in different environments [46]. Experimental studies conducted by Brett et al. [8] and Reznick [41] indicate that phenotypic plasticity in growth of fish depends on trophic conditions, more precisely on the amount of food actually available per individual. Depending on the case considered, the investigation of growth variability can contribute to a better understanding of the processes involved in fish growth in natural open systems, and help to determine the main limiting factors, i.e. the level of prey production, the number of fishes in competition, etc. Consequently, as fisheries substantially decrease population densities, they may possibly change growth patterns in exploited populations. Conversely, this change may have consequences on the indicators used for fisheries manage- 
ment. Beverton and Holt [5] showed by an empirical model that density-dependent growth should be taken into account for stock assessment of North sea plaice and haddock; otherwise the potential increases in yield expected from a reduced fishing effort or increased mesh size would be overestimated. Overholtz et al. [35] showed that taking into account the compensatory responses of the Northwest Atlantic mackerel stock leads, under certain conditions, to less optimistic yield projections than classical assessment. Also, Parma and Deriso [37] showed that neglecting growth variability when mortality is size-selective can lead to serious overestimation of optimal fishing levels. A detailed investigation of the possible factors involved in growth phenotypic plasticity is then required, as well as modelling efforts to incorporate these factors into population models. Attempts to model growth plasticity in situ were made for fresh-water ecosystems (e.g. $[17,26,56])$, but very few for marine environments [5, 34], notably because of the difficulties linked to the spatial scales of observation and measure. Continental environments may be more suitable for the development of detailed models that link environmental production to fish growth metabolism. However, such models are not readily applicable to marine ecosystems where either empirical approach or statistical analysis is used more often.

This study attempts to quantify the effects of several factors known to influence growth rates. We adopt a theoretical approach based on knowledge of the general processes involved in environmental productivity and fish growth. The North Sea herring population (Clupea harengus) was selected for these investigations because it showed large and well documented changes in abundance during the last decades $[9,15]$. This interannual variability in abundance is hypothesized to affect the amount of available food per individual. We then use the obtained model of growth phenotypic plasticity to show how predicted yield per recruit changes when age-specific weights are allowed to vary.

\section{METHODS}

\subsection{Data source}

There are three populations of herring in the North sea, named after their spawning ground location (Downs, Buchan and Dogger); these populations have different demographic and meristic characteristics [14, 30]. Our study applies only to the Downs population, for which growth data were available to us. The population is subject to exploitation during winter months along the French coast when adults migrate to their spawning ground. Sampling of herring from October to December in ICES statistical divisions VIId and IVc, ageing and length measurements are carried out by Ifremer in Boulogne-sur-Mer.
From age 2, adults of the three herring populations are known to mix on the feeding grounds in the northcentre of the North sea. Their overall abundance should then be considered when assessing densitydependent effects on Downs herring: their annual growth occurs mainly during their feeding phase, i.e. the one that follows the springtime bloom period [21, 30]. Abundance data were provided by cohort analysis conducted annually by the Advisory Committee on Fishery Management of the International Council for the Exploration of the Sea [2].

Records of sea surface temperature and windinduced turbulence collected by merchant ships were provided from the world database COADS (Comprehensive Ocean Atmospheric Data Set) [60] for the herring feeding area $\left(54-60^{\circ} \mathrm{N}\right.$ and $\left.0-4^{\circ} \mathrm{E}\right)$.

The data are available for a common period, from 1974 to 1990.

\subsection{Model description}

Animal growth rate results from the antagonistic effects of anabolism and catabolism [40]. The von Bertalanffy [55] model rests on two additional assumptions.

- Anabolism and catabolism terms are respectively proportional to body surface and weight:

$$
\frac{\mathrm{d} W_{a}}{\mathrm{~d} a}=\text { anabolism }- \text { catabolism }=H S_{a}-k W_{a}
$$

where $W_{a}$ is the weight of the fish of age $a, S_{a}$ the surface of the fish of age $a, H$ the rate of synthesis per unit of 'physiological surface' and $k$ is the rate of destruction of mass per unit mass.

- Growth is isometric such that:

$$
S_{a}=\mathrm{p} l_{a}^{2} \quad \text { and } \quad W_{a}=\mathrm{c} l_{a}^{3}
$$

where $l_{a}$ is the length of age $a$ fish, p and $\mathrm{c}$ are constants.

From the above, it follows that:

$$
\frac{\mathrm{d}\left(\mathrm{c} l_{a}^{3}\right)}{\mathrm{d} a}=H \mathrm{p} l_{a}^{2}-k \mathrm{cl} l_{a}^{3}
$$

The von Bertalanffy model is obtained by integrating:

$$
\begin{aligned}
& l_{a}=l_{\infty}\left(1-\mathrm{e}^{-K\left(a-a_{0}\right)}\right) \text { with } l_{\infty}=\lim _{a \rightarrow \infty} l_{a}=\frac{H \mathrm{p}}{3 \mathrm{c} K}, \\
& K=\frac{k}{3}, \quad l\left(a_{0}\right)=0
\end{aligned}
$$

In this model, growth depends only on fish age. To account for interannual variability in growth, we detail the bioenergetic processes (figure 1). Reasoning in a time step of 1 year, the individual rate of synthesis $H_{t}$ depends on $B_{t}$, the amount of food available in the year $t$ that a given fish shares with the whole popula- 


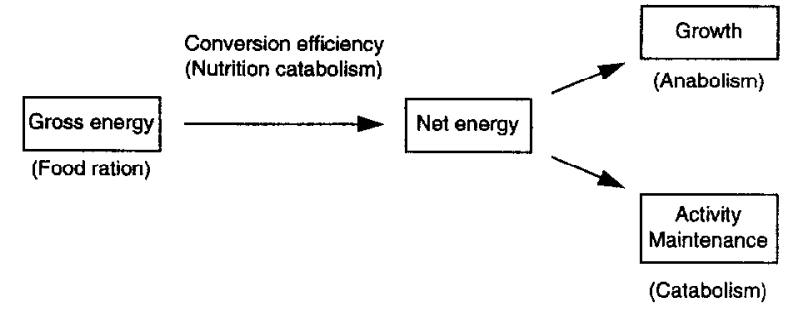

Figure 1. Conceptual model of the energy budget of fish metabolism (adapted from Brett and Groves [6])

tion (abundance $N_{t}$ ), and on the energy conversion efficiency $e_{\varepsilon}[36]$ :

$$
H_{i}=e_{\varepsilon} \frac{B_{t}}{N_{t}}
$$

The metabolic losses due to nutrition and assimilation activity (nutrition catabolism) are expected to be proportional to the amount of food consumed [54]; their variability is implicitly taken into account in the general term of anabolism (figure I). The term of catabolism only includes the losses due to processes supposed to be independent of fecding. In the frame of the von Bertalanffy model, only the parameter $l_{\infty}$ can therefore express an interannual variability of trophic conditions.

On the other hand, $B_{t}$ depends on $P_{t}$, the total biomass of prey produced in the environment over year $t$ :

$$
B_{t}=\frac{p_{t}}{p_{t}+m_{0}} P_{l}
$$

where $p_{t}$ is the rate of predation mortality and $m_{0}$ is the rate of other sources of mortality (predation by other species, environmental conditions, etc.), considered constant in our model.

For North sea herring (Downs stock) or other populations, several factors may induce $B_{t}$ to vary.

- Density-independent factors for $P_{t}$, the production of prey. North sea adult herrings feed on planktonic crustaceans, essentially on copepods Calanus $[10,30$, 45]. To estimate $P_{t}$, we used a measure of the environmental conditions that are known to affect the intensity of spring planktonic bloom, preceding the annual phase of herring nutrition [11]. The underlying mechanism is the stratification of the water column after a period of vertical transport of nutritive substances [20, $33,50]$. Two environmental factors are considered.

1) The gradient of sea surface temperature $(\triangle S S T)$ prior to the stratification of the water column (between February and April) [29]. Positive correlations between sea surface temperature and the amount of zooplankton were observed in the North sea $[1,13]$.

2) The wind-induced turbulence $(T)$ coincident with the setting up of the thermocline (April). Frequent strong winds in the critical month of the thermal strat- ification can lead to a delay in the initiation of the planktonic production (shortening of the production season), and even to a decrease in the production peak $[16,50]$.

Prey production, $P_{t}$ is thus predicted based on the importance of the spring bloom, by a linear approximation:

$$
P_{t}=\delta \Delta S S T_{t}+\gamma T_{t}+R_{0}
$$

where $\delta$ is supposed positive and $\gamma$ negative. $R_{0}$ is the enrichment of the environment in prey, independent of $\triangle S S T_{r}$ and $T_{t}$.

- Density-dependent factors for $p_{\text {, }}$, the rate of predation mortality. A negative relationship between individual growth and the abundance of North sea herring populations was shown by empirical studies $[9,10$, 23]. This supports the existence of an intraspecific competition resulting in density-dependent growth. By contrast, the existence of interspecific competition in the nutrition area of Downs adult herrings is not clearly established.

Then, the rate of predation by herrings is hypothesized to be a linear function of all three herring populations' abundance $N_{t}$ with $\alpha$ positive:

$$
p_{t}=\alpha N_{t}
$$

Combining equations (3) to (6), we obtain:

$$
H_{t}=\frac{e_{\varepsilon} \alpha\left(\delta \Delta S S T_{t}+\gamma T_{t}+R_{0}\right)}{\alpha N_{t}+m_{0}}
$$

By identification with the von Bertalanffy term of anabolism (Eq. 1 and 2), we obtain the final model:

$$
\begin{aligned}
& l_{a, t}=\left(\frac{\theta_{1} \Delta S S T_{t}+\theta_{2} T_{t}+\theta_{3}}{1+\theta_{4} N_{t}}\right)\left(1-\mathrm{e}^{-K\left(a-a_{0}\right)}\right) \\
& \text { with } \theta_{1}=\frac{e_{\varepsilon} \alpha \mathrm{p} \delta}{3 \mathrm{c} K m_{0}}, \theta_{2}=\frac{e_{\varepsilon} \alpha \mathrm{p} \gamma}{3 \mathrm{c} K m_{0}}, \\
& \theta_{3}=\frac{e_{\varepsilon} \alpha \mathrm{p} R_{0}}{3 \mathrm{c} K m_{0}}, \theta_{4}=\frac{\alpha}{m_{0}}
\end{aligned}
$$

By using the analogy with the von Bertalanffy model, we implicitly considered $l_{\infty}$ constant up to age $(a-1)$ and let it vary only for year $t$, which is conceptually not in accordance with our hypotheses. Nevertheless, in the statistical model described below we used an autoregressive term, which introduces length at age $(a-1)$, year $(t-1)$ in the equation. Thereby, we take into account all previous growth (and thus the past variations of the environment) synthesized by $l_{a-1, t-1}$. To solve the equation of growth plasticity while taking into account the interannual variability of $l_{\infty}$, two methods may have been used: i) a piece-wise integration on a time step of 1 year (the period within which $l_{\infty}$ is considered constant) over the whole life of a cohort, but the resulting model has too many parameters to be fitted with the available data; ii) integration over a time period of 1 year $[a, t ; a+1, t+1]$ would provide a sim- 
pler model but the covariable $a$ would disappear from the equation; this model would not take into account the progressive slowing down of fish growth with age, up to an asymptotic size. The statistical model proposed below makes it possible to fit a growth model that takes into account the interannual variability of trophic conditions as well as the slowing down of fish growth with age.

\subsection{Estimation of the parameters}

Let the observed lengths $l_{l}, \ldots, l_{n}$ be a realization of the random vector $L_{l}, \ldots, L_{n}$, the components of which can be written as (basic model a):

$L_{i_{a, 1}}=\mathrm{g}\left(\mathbf{x}_{i_{a, 1}}, \theta\right)+w_{i_{a, t}} \quad i=1, \ldots, n$

where

$\mathrm{g}\left(\mathbf{x}_{i_{a,}}, \theta\right)=\left(\frac{\theta_{1} \Delta S S T_{t}+\theta_{2} T_{t}+\theta_{3}}{1+\theta_{4} N_{t}}\right)\left(1 \cdots \mathrm{e}^{-K\left(a-a_{0}\right)}\right)$

$\mathbf{x}$ matrix of variables, $\theta=\left(\theta_{1}, \ldots, \theta_{p}\right)$ vector of parameters.

As the obscrvations of mean lengths correspond to the following of cohorts in the course of time, the assumption of the independence of the errors $w_{i}$ does not hold. Therefore an autoregressive model of order 1 seems more suitable:

$$
\begin{aligned}
& L_{i_{a, t}}=\mathrm{f}\left(\mathbf{x}_{i_{a, t}}, \theta\right)+\varepsilon_{i_{a, t}} \quad i=1, \ldots, n \\
& \text { with } \quad w_{i_{a, t}}=\rho w_{i-1_{a-1, t-1}}+\varepsilon_{i_{a, t}} \quad|\rho|<1, \\
& \varepsilon_{i_{a, t}}, \ldots, \varepsilon_{n_{a, t}}-N\left(0,\left(1-\rho^{2}\right) \sigma_{w}^{2}\right)
\end{aligned}
$$

The residuals $\varepsilon_{i_{a, 1}}$ are not correlated [19].

The statistical model can then be represented by the final form (full model $b$ ):

$$
L_{i_{a, i}}=\mathbf{f}\left(\mathbf{x}_{i_{a, i}}, \theta\right)+\varepsilon_{i_{a, i}}, \quad i=1, \ldots, n
$$

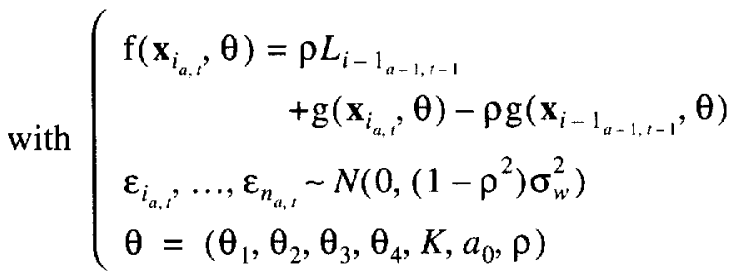

The parameters of the model are estimated by a Gauss-Newton algorithm of the S-plus application [12], and from annual data of mean lengths at age. We only used means calculated from samples of at least ten observations, an arbitrary compromise to obtain a sufficient number of reliable data $(n=53)$.

We conducted tests to determine if $\theta$ varies in the whole set of parameters $\Theta(\operatorname{dim}=7)$ or in a subset $\Theta_{0}$ of $\Theta(\operatorname{dim}<7)$, in order to identify the most parsimonious model. A likelihood ratio test was used to compare the nested models [22].

An error analysis was carried out using the method of Majkowski et al. [28] to check if the propagation of the errors committed on the parameter estimates is not too high. Monte-Carlo simulations were performed, assuming that each parameter is normally distributed with mean and variance corresponding to those estimated by fitting the model. The sensitivity of the model to each parameter, as well as its global sensitivity (taking into account the covariances between the estimates of the parameters), were assessed in terms of coefficients of variation of mean length at age [18]. Five hundred Monte-Carlo simulations were performed to produce frequency distributions of variance estimates.

\subsection{Simulations of yield per recruit}

Yield per recruit $Y r$ represents the long-term potential production of a stock. $Y r$ quantifies the complex combination between the number of fish caught, which increases with fishing pressure, and the mean individual weight which, by contrast, decreases [27]. The model used was that proposed by Thompson and Bell [52] namely:

$$
\begin{aligned}
& Y r= \\
& \frac{1}{N_{a_{r}}}\left[\sum_{a=a_{r}}^{A} N_{a_{r}}\left(\prod_{i=a_{r}}^{a} e^{-\left(F_{i}+M_{i}\right)} \frac{F_{a} W_{a}}{F_{a}+M_{a}}\left(1-\mathrm{e}^{-\left(F_{a}+M_{a}\right)}\right)\right]\right.
\end{aligned}
$$

where $a_{r}$ and $A$ are respectively the age at recruitment and terminal age, $N_{a r}$ the number of recruits, $F_{a}$ and $M_{a}$ the rates of agc-specific fishing and natural mortality, respectively (see [5]).

For a vector of constant weights at age, a reference yield per recruit, $Y r_{\text {ref }}$, was first estimated and compared with that obtained from weights depending on cohort abundance on the basis of the growth plasticity model (environmental variables are taken to be equal to the mean of the observations over the period 1974 1990). Due to the lack of data, the model of growth plasticity can not be fitted for mean weights at age but rather for mean lengths at age instead (the size of weights at age samples is often less than 10). The translation from mean lengths at age to mean weights at age is realized from the allometry relation $W_{i}=c L_{i}^{3}$ which can be fitted on abundant individual data. The least squares criterion weighted by the inverse of the regressor $L_{i}^{3}$ was used to fit the model and meets the assumption of homoscedasticity.

As the model of phenotypic plasticity is only valid for ages superior to 2 , we considered $W_{0}$ and $W_{1}$ constant ( $W_{0}$ obtained from the literature [2] and $W_{1}$ from the allometric relation). Furthermore, we used the recruitment value $N_{a r}=N_{0,1974-90}\left(0^{+}\right.$being the age of 
herring recruitment) to initialize the simulations of yield per recruit.

\section{RESULTS}

\subsection{Selection of a growth model}

For the model (b), the $t$-values associated with the estimates of $\theta_{1}$ and $\rho$ were not statistically significant at $\alpha=0.05\left(t_{\theta 1}=1.948, t_{0}=0.780\right)$, i.e. either the data do not support estimation of these parameters, or one or both of the parameters can be neglected in the model.

To reduce the number of parameters, the following alternatives were then tested:

- model (c) without temperature effect: $\Theta_{0}=\left\{\theta_{1}=0\right\}$;

- model (d) without autocorrelation: $\Theta_{0}=\{\rho=0\}$;

- model (e) without temperature effect nor autocorrelation: $\Theta_{0}=\left\{\theta_{1}=0\right.$ and $\left.\rho=0\right\}$.

Model (e) was rejected by the likelihood ratio test at $\alpha=0.05$ (table I). For models (c) and (d), the residual variance estimates were low and of similar magnitude. The test of Shapiro and Wilk [47] showed that for both models (c) and (d), the hypothesis of residual normality is not rejected (respectively $P=0.910$ and 0.188 ).

\section{However:}

- type II error for the test of Shapiro and Wilk is much lower in the case of model (c);

- the estimates $\hat{K}$ and $a_{0}$ are highly correlated for model (d) (0.985), which is an indication of model inadequacy [4].

Model (c) seems therefore the most appropriate to describe the plasticity of growth (figure 2). The selected non-linear regression equation is:

$$
\begin{aligned}
& \mathrm{f}\left(\mathbf{x}_{i_{a, t}}, \theta\right)=\rho L_{i-1_{a-1, t-1}}+\mathrm{g}\left(\mathbf{x}_{i_{a, i}}, \theta\right)-\rho \mathrm{g}\left(\mathbf{x}_{i-1_{a-1, t-1}}, \theta\right) \\
& \text { with } \mathrm{g}\left(\mathbf{x}_{i_{a, t}}, \theta\right)=\left(\frac{\theta_{2} T_{1}+\theta_{3}}{1+\theta_{4} N_{t}}\right)\left(1-\mathrm{e}^{-K\left(a-a_{0}\right)}\right)
\end{aligned}
$$

Estimates of the parameters are presented in table II.

For a coefficient of variation (CV) of $30 \%$ for each parameter, the error analysis showed that length was mainly sensitive to parameter $\theta_{3} \quad(\mathrm{CV}=17 \%)$, $K(\mathrm{CV}=8 \%)$ and $\rho(\mathrm{CV}=6 \%)$, whereas the model was not very sensitive to parameters $\theta_{2}$ and $\theta_{4}$ (table III).

Table I. Results of the hypotheses tests for the plastic growth models (c), (d) and (e). Model (b) is the initial plastic growth model that included sea surface temperature, wind-induced turbulence and herring abundance. $\Theta$ is the space of model (b) parameters, of which $\theta_{1}$ is the parameter associated with temperature and $\mathrm{r}$ the autoregressive parameter.

\begin{tabular}{lccc}
\hline & & Model (b) & \\
\cline { 2 - 4 } & Model (c) & dim $\Theta=7 \quad \sigma_{\varepsilon}=0.412$ & Model (e) \\
\cline { 2 - 4 } & $\theta_{1}=0$ & Model (d) & $\theta_{1}=0$ and $\rho=0$ \\
$\mathrm{H}_{0}$ & 0.418 & $\rho=0$ & 0.440 \\
$\sigma_{\varepsilon}$ & 2.617 & 0.410 & 9.130 \\
Statistic of the likelihood ratio & $\mathrm{H}_{0}$ not rejected & 0.477 & $\mathrm{H}_{0}$ rejected \\
Conclusion (level of significance 0.05$)$ & 0.985 & 0.958 & 0.958 \\
$W$ (statistic of Shapiro and Wilk) & 0.910 & 0.188 & 0.182 \\
$P\left(W<W(n, \alpha) / \mathrm{H}_{0}\right)$ & & not rejected & \\
\hline
\end{tabular}

Figure 2. Observed (circles, triangles) and fitted (crosses, lines) mean lengths at age (ages 2 to 6) of North sea herring (Downs stock) from the plastic growth model (c), i.e. taking into account herring abundance and the wind-induced turbulence coincident with the spring stratification of the water column $(n=53)$.

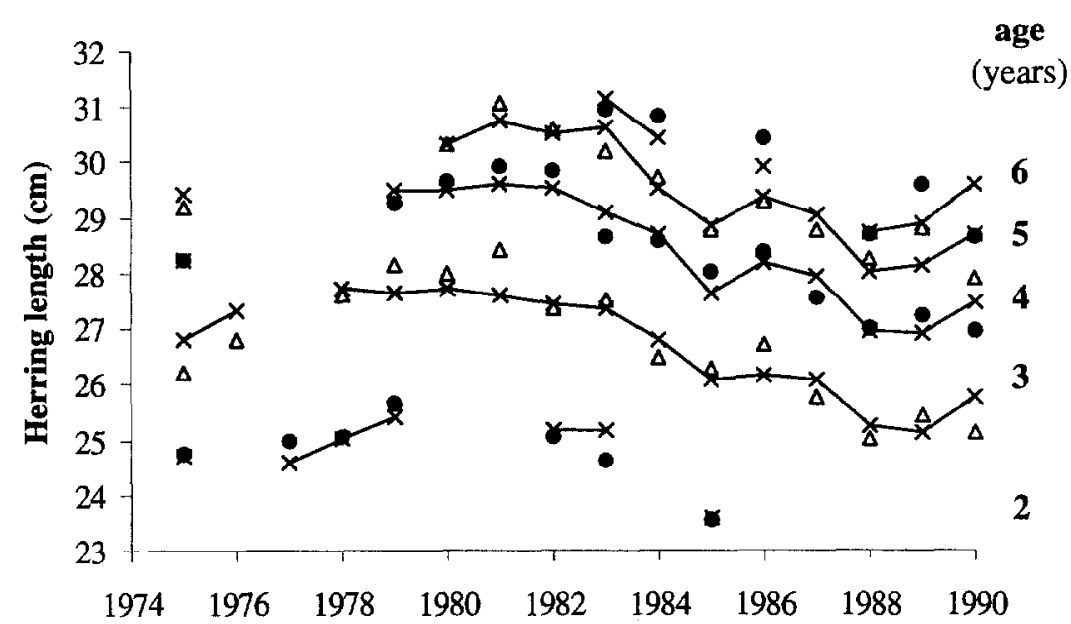

Aquat. Living Resour. 11 (5) (1998) 
Table II. Results of the least squares estimation of model (c) parameters ( $n=53$ and $\hat{\sigma}_{\varepsilon}=0.418$ ). The plastic growth model (c) takes into account herring abundance and the turbulence coincident with the spring stratification of the water column.

\begin{tabular}{|c|c|c|c|c|c|c|c|c|c|}
\hline & Estimate & $\mathrm{SD}$ & $|t|$ value & \multicolumn{6}{|c|}{ Matrix of correlation } \\
\hline$K$ & 0.649 & $7.877 \mathrm{e}^{-2}$ & 8.237 & 1 & & & & & \\
\hline$\theta_{2}$ & $-1.024 \mathrm{e}^{-3}$ & $3.073 \mathrm{e}^{-4}$ & -3.331 & -3.331 & 1 & & & & \\
\hline$\theta_{3}$ & 33.549 & 0.565 & 59.423 & -0.576 & -0.506 & 1 & & & \\
\hline$\theta_{4}$ & $7.138 \mathrm{e}^{-12}$ & $9.522 \mathrm{e}^{-13}$ & 7.497 & 0.013 & -0.193 & 0.55 & 1 & & \\
\hline$a_{0}$ & 1.564 & 0.593 & 2.638 & 0.377 & -0.136 & 0.097 & 0.269 & 1 & \\
\hline$\rho$ & 0.464 & $4.438 \mathrm{e}^{-2}$ & 10.671 & -0.824 & 0.057 & 0.614 & 0.104 & 0.201 & 1 \\
\hline
\end{tabular}

Table III. Results of sensitivity analysis for growth model (c). The coefficients of variation (CV) are obtained by 500 Monte-Carlo simulations of a normal distribution for each parameter, the $\mathrm{CV}$ of the parameters corresponding to the arbitrary value of $30 \%$ and to the least squares estimation of the model (c) (cf. table II). Last line: correlated normal distributions for all parameters.

\begin{tabular}{lccc}
\hline & $\begin{array}{c}\text { CV of length }(\%) \\
\text { when parameters CVs }=30 \%\end{array}$ & $\begin{array}{c}\text { Parameters CVs (\%) according } \\
\text { to the results of the model (c) fit }\end{array}$ & CV of length (\%) \\
\hline$K$ & 8.142 & 12.140 & 2.858 \\
$\theta_{2}$ & 0.462 & 30.020 & 0.473 \\
$\theta_{3}$ & 16.868 & 1.683 & 1.018 \\
$\theta_{4}$ & 0.723 & 13.339 & 0.339 \\
$a_{0}$ & 1.164 & 37.906 & 1.579 \\
$\rho$ & 6.353 & 9.372 & 1.975 \\
All parameters & 18.812 & & 1.158 \\
\hline
\end{tabular}

The error introduced simultaneously on all parameters decreased while propagating in the model: the simulated $\mathrm{CV}$ was equal to $18.8 \%$ against initial parameters CVs of $30 \%$. The use of CVs obtained from the fit of model (c), showed the relatively high influence of uncertainty on both parameters $K$ and $\rho$.

\subsection{Influence of the phenotypic plasticity on yield per recruit}

Since the allometric model: $W_{i}=c L_{i}^{3}+u_{i}[u \sim$ $\left.\mathrm{N}\left(0, \sigma_{u i}\right)\right]$ showed a good fit to the North sea herring data $\left(\hat{c}=8.3 \mathrm{mg} \cdot \mathrm{cm}^{-3}, \hat{\sigma}_{c}<0.1, \mathrm{R}^{2}=0.984, P<10^{-4}\right)$, we used length plasticity model (c) to predict yield per recruit.

The plastic growth model was elaborated for lengths of ages superior to 2 of Downs herring. As weights at ages 0 and 1 did not take into account a phenotypic plasticity and were approximated, we investigated the error propagated in the simulations of yield per recruit. Intuitively, the error made on $W_{0}$ should not have an important impact on yield per recruit, since the value of $W_{0}$ and the fishing mortality on this age class are low. This was also true for weight at age 1 , except that the corresponding length plays a part in the initialization of the autoregressive model of growth, more precisely in the calculation of length at age 2 . But MonteCarlo simulations showed that the error introduced on $L_{1}$ decreased steeply with age (figure 3 ).

Curves of yield per recruit (expressed in $\mathrm{kg} /$ recruit) were established for multipliers $\mu$ of the fishing mortality vector $\mathrm{F}_{92-94}$ [2] varying between 0 and 3 (figure 4). Two simulations were performed respectively, with a constant vector of age-specific weights estimated by the mean of the observations for 1992-

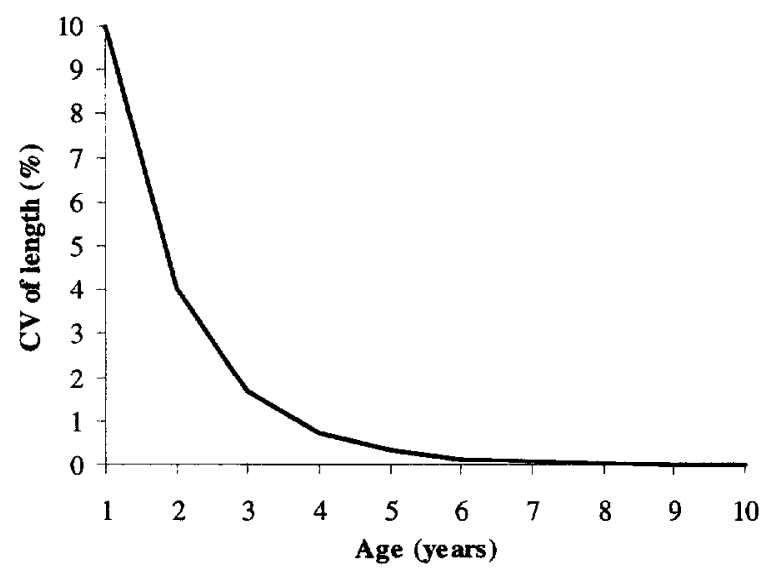

Figure 3. Propagation of the error made on length at age 1 in the autoregressive plastic growth model (c). The coefficients of variation (CV \%) of length against age are obtained by 500 Monte-Carlo simulations of a normal distribution of the length at age 1 , for a $C V$ of $10 \%$. The parameters and the other variables of the model are constant and equal respectively to the model (c) estimated values, and to the mean of available data.

1994, and with a vector of density-dependent weights at age. The vector of constant mean weights at ages, as well as the fitted model, are only valid for the Downs stock. However, we were bound to use vectors of natural and fishing mortality rates resulting from a VPA combining together the three North sea herring stocks; we hence assume that these three stocks, which are subjected to a global assessment, have similar patterns of growth phenotypic plasticity.

The curve obtained with constant weights at age indicates that the exploitation level of the entire fishery 


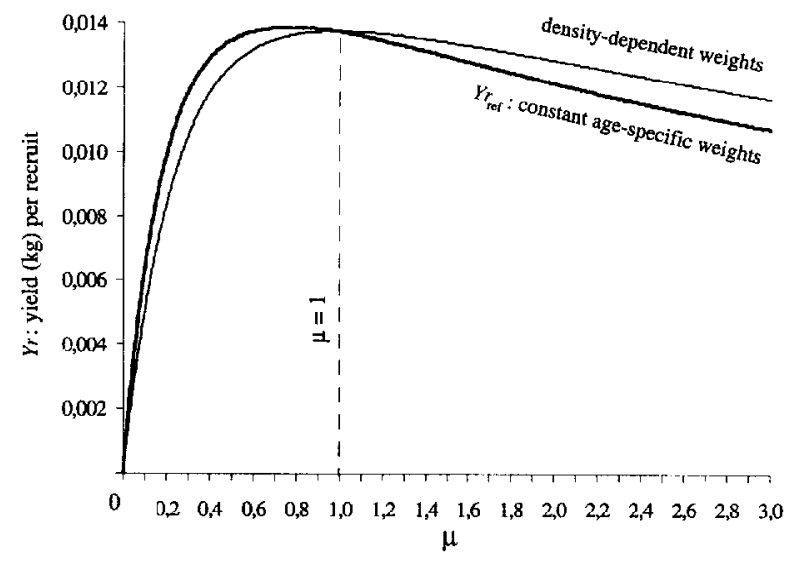

Figure 4. Yield per recruit of the North sea herring fisheries as a whole against a multiplier $\mu$ of a vector of fishing mortality which is representative of the current exploitation diagram. The input vectors are: the vectors of natural mortality $\mathrm{M}$ and of fishing mortality $\mathrm{F}_{92-94}$ [2], a vector of mean age-specific weights stemming from available data and a vector of weights varying with cohort abundance, according to the plastic growth model (c) (turbulence is equal to the mean of observations over the period 1974-1990).

in 1992-1994 $(\mu=1)$ caused a situation of slight overexploitation of North sea herring. For the other curve, this level of exploitation roughly corresponds to the maximum of yield per recruit. Thus, even if the global weight of a cohort decreases with the intensification of fishing pressure (mean age becomes younger), the combination with the parallel increase of the mean weight at ages (growth rate increases as fish abundance decreases) resulted in a more optimistic assessment; from the threshold $\mu=1$ (figure 4), values of yield per recruit taking into account a density-dependent growth were superior to those of $Y r_{\text {ref }}$. Conversely, the use of constant growth overestimates the positive effects of reducing fishing effort.

\section{DISCUSSION}

\subsection{A model for growth phenotypic plasticity}

The proposed model is a generalization of the von Bertalanffy model [55]. The parameters $K$ and $a_{0}$ remain constant and only $l_{\infty}$ varies with trophic conditions.

The estimated value of $a_{0}=1.564$ is, however, neither in accordance with the literature $\left(a_{0}=-0.78\right.$ [24]), nor consistent since $a_{0}$ is the theoretical age of length zero. This result may stem from the fact that the von Bertalanffy model does not describe juvenile growth as would a model with an inflection point, for example the Gompcrtz model [39]. In addition, it is not possible to estimate $a_{0}$ with precision in our study: on the one hand, younger ages ( 0 and 1$)$ are not included in the model; and on the other hand, estimates of length at age 2 require data of mean lengths at age 1 , for which most sample sizes are less than 10 . To avoid the constraints due to the low sample sizes, a least squares criterion weighted by the respective size of the samples may be used. But as the latter are very variable, some age classes would have an overwhelming weight, without any theoretical ground. Furthermore, the model proves robust to the uncertainty linked to the parameter $a_{0}$ (CV of length equals $1.2 \%$ from a $\mathrm{CV}$ of $30 \%$ for $\left.a_{0}\right)$.

The von Bertalanffy model parameter $l_{\infty}$ is in our model a function of the turbulence coincident with the thermal stratification of the water column, and of annual herring abundance. The estimate of the parameter $\theta_{2}$ associaled with turbulence is negative: this is consistent with the hypothesis adopted while constructing the model. The parameter $\theta_{1}$ associated with the gradient of sea surface temperature, is neglected in the final model. We therefore conclude that sea surface temperature gradient has a weak influence on North sea herring growth variability for the period 1974 1990. Whether this results from a low influence of temperature on the enrichment in prey can not be established here.

The error analysis suggests that the model is not very sensitive to the uncertainties on parameters $\theta_{2}$ and $\theta_{4}$ (respectively, coefficients of turbulence and herring abundance). A first interpretation would suggest that these parameters can be neglected in the model but it is without considering the variations in turbulence and herring abundance which are high (CVs of $31 \%$ and $77 \%$ respectively for 1974-1990). Given the fact that the model is more sensitive to the $\mathrm{CV}$ of $\theta_{4}$ and that the $\mathrm{CV}$ of abundance is higher than the one of turbulence, we can also notice that, in the particular case of North sea herring and for the investigated period, herring abundance variability seems to play a more important role than turbulence variability. This is consistent with many previous studies which concluded that herring abundance had a greater effect on growth than environmental variables (see [51]).

The model of growth phenotypic plasticity is used to explore the consequences of taking into account density-dependence of growth on yield per recruit. The difference between the two curves is not very large and is therefore unlikely to have an effect on subsequent advice in the case of the North sea herring. However, for other patterns of exploitation or for other species (leading to steeper slopes for instance), accounting for density-dependent growth can be of interest since it leads to more optimistic assessments for high fishing mortality. This result is in accordance with the conclusion of Beverton and Holt [5] for North sea plaice and haddock, although they used more empirical relationships between growth and population density. The comparison with the results of Overholtz et al. [35] for Northwest Atlantic mackerel is more difficult, since the authors assume that maturity and predation mortality are also density-dependent. However, for their range of low fishing mortality, their results are in 
accordance with ours: the standard model is more optimistic than the density-dependent model with respect to yield per recruit.

\subsection{Density dependence of fish growth}

The negative relation between herring abundance and growth suggested by our model is in agreement with most of previous studies. Iles [23], Hubold [21] and Burd [10] reported similar relations for North sea herring. Wyszynski [61] and Parmanne [38] reported them for Baltic sea herring, Toresen [53] for Norway herring, and Anthony [3] for Maine herring. By contrast, other studies conclude that growth is not densitydependent. For instance, Moores and Winters [32] suggest that growth is mainly determined by the sea temperature prevailing during the annual phase of herring growth. They conclude it from linear regression concerning annual relative growth rates $\left(l_{a+1}-l_{a}\right) / l_{a}$ but in our model, we can see that this rate can not depend linearly on herring abundance (Eq. 7). Similarly, Tanasichuk [51] concludes from linear regressions of growth rate on adult biomass and environmental variables that growth in mass, but not in length, is affected by these factors. This author therefore casts doubt on the utility of length as an indicator of fish growth variability. We suggest that the influence of these factors on growth in length can be detected by non-linear models. A more surprising result is obtained by Sinclair et al. [48], who advocate a dome-shaped relation between growth and abundance of the Nova Scotia herring. On a low abundance range, the observed positive relation would be due to a better detection of planktonic patches when school densities increase.

In natural marine populations, density-dependent growth is frequently observed (e.g. [5, 34, 44]). The negative relation between fish growth and density is usually attributed to a negative relation between the amount of food consumed per individual and fish density. Our study does not make exception to this assumption, which is supported by experimental works $[7,41,58]$. The negative relation between fish density and the amount of food available per individual can hardly be demonstrated in situ. This is partly because in marine environments, density is easily confused with abundance. In closed areas like lakes, density indices can be used to show density-dependent growth $[6,26,42]$. In the marine environment, the observation of abundance-dependent growth leads to two different hypotheses: i) fish schools cover locally the same distribution area whatever the abundance level may be, and then an effective increase of school density would decrease the portion of available prey per individual; and ii) the distribution area increases with stock abundance (density remaining the same). Consequently, individuals would have to prospect a larger range to find ungrazed areas; the abundance-dependent growth is then explained by a higher cost in foraging energy combined with the low level of the environment enrichment in prey.

\subsection{Density-dependent growth and the trade-off between growth and reproduction}

Here, we consider that an energy surplus causes an increase in length growth. This is most probable in immature fish, whereas after sexual maturity surplus energy may be allocated either to growth or to reproduction [57]. The trade-off between growth and reproduction is the most documented phenotypic trade-off between life-history traits, especially in species with indeterminate growth [49].

The patterns of this trade-off change during life.

- Before maturity, high food availability, resulting in rapid growth, allows an increase in size at maturity and a decrease in age at maturity, as suggested by the experiments of Reznick [41]. This may be another important consequence of density-dependent growth, which is usually not taken into account for stock projections using yield per recruit or spawning biomass per recruit. The influence of density-dependent growth on age and size at maturity and on the estimates of spawning biomass per recruit should be investigated, although it was beyond the scope of this paper and the data available.

- After sexual maturity, fish do not immediately attain their maximum size. The issue is then to choose which proportion of energy surplus is to be allocated to growth and which part to reproduction: the general process of growth is a balance between somatic growth and gonadic growth [25]. In the short term, the allocation of surplus energy to reproduction would favour a high recruitment for the current year. In the longer term, however, the allocation of this surplus to growth would improve future reproduction since fecundity increases with size, and the reproductive output over the whole life cycle may be increased. Our assumption that the condition factor $c$ is constant means that the proportion of surplus energy allocated to growth is constant. This assumption can be reasonably admitted for the age interval considered in the fit of our model, where fishes re young and still have significant growth rates.

- When fish approach their maximum length, most of the energy surplus is allocated to reproduction. Thus the variability of length at age is not a good index for abundance variations: Winters and Wheeler [59] show that the condition factor $c$ of Nova Scotia herring varies with abundance, and conclude that surplus energy is allocated to gonadic growth rather than somatic growth. This result does not conflict with ours, since these authors sampled herrings with length higher than $30 \mathrm{~cm}$, i.e. herrings which have almost reached their maximum length: their increase in length with age is then small in comparison with the annual increase in weight due to reproduction. 


\section{CONCLUSION}

A theoretical model of growth plasticity in North sea herring length in relation to trophic conditions is developed. This model brings together the approaches advocating on the one hand, the density-dependence of growth and on the other hand, the influence of environmental factors. In the investigated system, the environ- ment is relatively stable in terms of productivity. Density-dependence (or more specifically abundancedependence) then plays a prominent role in the phenotypic plasticity of growth and the dependent life history traits. By contrast, in very productive and unstable environments, environmental factors would probably take a larger part in the variability of fish growth. These aspects should be assessed by a comparative approach.

\section{Acknowledgements}

We thank Yves Vérin and Pascal Lorance (Ifremer, Boulogne-sur-Mer) for providing herring sample and survey records, and Claude Roy for providing COADS data. This paper was greally improved by comments from Olivier Maury, Philippe Gros, Marc Labelle, Francis Laloë and Alain Maucorps, and four anonymous referees.

\section{REFERENCES}

[1] Anonymous, Continuous plankton records: the North Sea in the 1980s, ICES Mar. Sci. Symp. 195 (1992) 243-248.

[2] Anonymous, Report of the herring assessment working group for the area south of $62^{\circ} \mathrm{N}$, ICES C.M. / Assess $13,1,1995,169 \mathrm{p}$.

[3] Anthony V.C., The density dependence of growth of the Atlantic herring in Maine, Rapp. P.V. Réun. Cons. Int. Explor. Mer 160 (1971) 197-205.

[4] Bates D.M., Watts D.G., Nonlinear Regression Analysis and its Applications, John Wiley \& sons, New York, $1988,365 \mathrm{p}$.

[5] Beverton R.J.H., Holt S.J., On the dynamics of exploited fish populations, Fishery Investigations, Series II, vol. 19, Her Majesty's Stationery Office, London, 1957, $533 \mathrm{p}$.

[6] Boisclair D., Leggett W.C., Among-population variability of fish growth: III. Influence of fish community, Can. J. Fish. Aquat. Sci. 46 (1989) 1539-1550.

[7] Brett J.R., Groves T.D.D., Physiological energetics, in: Hoar W.S., Randall D.J., Brett J.R. (Eds.), Bioenergetics and Growth (Fish Physiology, vol. VIII), Academic Press, 1979, pp. 279-352.

[8] Brett J.R., Schelbourn J.E., Shoop C.T., Growth rate and body composition of fingerling sockeye salmon, Oncorhynchus nerka, in relation to temperature and ration size, J. Fish. Res. Board Can. 26 (1969) 23632394.

[9] Burd A.C., Long-term changes in North sea herring stocks, Rapp. P.V. Réun. Cons. Int. Explor. Mer 172 (1978) 137-153.

[10] Burd A.C., Density-dependent growth in North sea herring, ICES CM/H: 4, 1984, 5 p.

[11] Burd A.C., Cushing D.H., Growth and recruitment to the North sea herring stocks, Fish. Invest. Ser. 223 (1962) $71 \mathrm{p}$.

[12] Chambers J.M., Hastie T.J., Statistical models, Wadsworth S., Brooks (Eds.), Cole Computer Science Series, Pacific Grove, California, 1992, 608 p.
[13] Colebrook J.M., Continuous plankton records: phytoplankton, zooplankton and environment, North-East Atlantic and North Sea, 1958-1980, Oceanol. Acta 5 (1982) 473-480.

[14] Cushing D.H., The unity of the Downs herring stock, and its degree of mixing with other stocks in the northern and central North Sea, in: Cushing D.H., Bridger J.P. (Eds.), The Stock of Herring in the North Sea and Changes due to Fishing, Fishery Investigations, London, Series II, vol. 15, 1966, pp. 1-62.

[15] Cushing D.H., A short history of the Downs stock of herring, ICES J. Mar. Sci. 49 (1992) 437-443.

[16] Dickson R.R., Kelly P.M., Colebrook J.M., Wooster W.S., Cushing D.H., North winds and production in the eastern North Atlantic, J. Plankton Res. 10 (1988) 151169.

[17] Fox M.G., Food consumption and bioenergetics of young-of-the-year walleye (Stizostedion vitreum vitreum): model predictions and population density effects, Can. J. Fish. Aquat. Sci. 48 (1991) 434-441.

[18] Gardner R.H., O'Neill R.V., Mankin J.B., Carney J.H., A comparison of sensitivity analysis and error analysis based on a stream ecosystem model, Ecol. Model. 12 (1981) 173-190.

[19] Glasbey C.A., Nonlinear regression with autoregressive time series error, Biometrics 36 (1980) 135-140.

[20] Gran H.H., Braarud T., A quantitative study of the phytoplankton in the Bay of Fundy and the Gulf of Maine, J. Biol. Board Can. 1 (1935) 279-433.

[21] Hubold G., Variations in growth rate and maturity of herring in the North sea in the years 1955-1973, Rapp. P.V. Réun. Cons. Int. Explor. Mer 172 (1978) 154-163.

[22] Huet S., Jolivet E., Messéan A., La régression nonlinéaire, méthodes et applications en biologie, Inra, Paris, 1992, 236 p.

[23] Iles T.D., Growth studies on North sea herring III, The growth of East Anglian herring during the adult stage of the life history for the years 1940 to 1967 , J. Cons. Int. Explor. Mer 33 (1971) 386-420.

[24] Jennings S., Beverton R.J.H., Intraspecific variation in the life history tactics of Atlantic herring stocks, ICES J. Mar. Sci. 48 (1991) 117-125. 
[25] Jones R., Towards a general theory of population regulation in marine teleosts, J. Cons. Int. Explor. Mer 45 (1989) 176-189.

[26] Korman J., Webb T.M., Parkinson E., Large lakes Kokanee model, version 2.0, user's guide, Fisheries Project Report RD35, 1993, 70 p.

[27] Laurec A., Le Guen J.C., Dynamique des populations marines exploitées, Tome I - Concepts et modèles, Publications du Centre National pour l'Exploitation des Océans, Rapp. Scient. Techn. 45, 1981, 120 p.

[28] Majkowski J., Ridgeway J.M., Miller D.R., Multiplicative sensitivity analysis and its role in development of simulation models, Ecol. Model. 12 (1981) 191-208.

[29] Mann K.H., Lazier J.R.N., Dynamics of Marine Ecosystems. Biological-Physical Interactions in the Oceans, Blackwell Scientific Publications, Boston, $1991,466 \mathrm{p}$.

[30] Maucorps A., Biologie et pêche du hareng en mer du Nord. Son exploitation rationnelle, Sci. Pêche 186 (1969) 1-18.

[31] Millner R.S., Whiting C.L., Long-term changes in growth and population abundance of sole in the North Sea from 1940 to the present, ICES J. Mar. Sci. 53 (1996) 1185-1195.

[32] Moores J.A., Winters G.H., Growth patterns in a Newfoundland Atlantic herring (Clupea harengus harengus) stock, Can. J. Fish. Aquat. Sci. 39 (1982) 454-461.

[33] North Sea Task Force, North sea quality status report, 1993, $132 \mathrm{p}$.

[34] Overholtz W.J., Density-dependent growth in the Northwest Atlantic stock of Atlantic mackerel (Scomber scombrus), J. Northw. Atl. Fish. Sci. 9 (1989) 115-121.

[35] Overholtz W.J., Murawski S.A., Michaels W.L., Impact of compensatory responses on assessment advice for the Northwest Atlantic mackerel stock, Fish. Bull. 89 (1991) 117-128.

[36] Paloheimo J.E., Dickie L.M., Food and growth of fishes, I. A growth curve derived from experimental data, J. Fish. Res. Board Can. 22 (1965) 521-542.

[37] Parma A.M., Deriso R.B., Dynamics of age and size composition in a population subject to size-selective mortality: effects of phenotypic variability in growth, Can. J. Fish. Aquat. Sci. 47 (1990) 274-289.

[38] Parmanne R., Changes in the growth of herring in the Northern Baltic Sea in 1970-1991, ICES C.M. 1992/J 42 (1992) 19.

[39] Pennington M.R., Fitting a growth curve to field data, in: Ord J.K., Patil G.P., Tallic C. (Eds.), Statistical Distributions in Ecological Work, International Cooperative Publishing Co., Fairland, Maryland, 1979, pp. 419-428.

[40] Pütter A., Wachstumsähnlichkeiten, Fuegers Arch. Gesamte Physiol. Menschen Tiere 180 (1920) 298-340.

[41] Reznick D.N., Norms of reaction in fishes, in: Stokes T.K., McGlade J.M., Law R. (Eds.), The Exploitation of Evolving Resources, Lecture Notes in Biomathematics, vol. 99, Springer-Verlag, Berlin, 1993, pp. 72-90.

[42] Rieman B.E., Myers D.L., Influence of fish density and relative productivity on growth of Kokanee in ten oligotrophic lakes and reservoirs in Idaho, Trans. Am. Fish. Soc. 121 (1992) 178-191.

[43] Rijnsdorp A.D., van Leeuwen P.I., Changes in growth of North sea plaice since 1950 in relation to density, eutrophication, beam-trawl effort, and temperature, ICES J. Mar. Sci. 53 (1996) 1199-1213.

[44] Ross M.R., Almeida F.P., Density-dependent growth of Silver Hakes, Trans. Am. Fish. Soc. 115 (1986) 548554.

[45] Savage R.E., The food of North sea herring, 1930-34, Fish. Invest. Ser. 215 (1937) 60.

[46] Schmalhausen I.I., Factors of Evolution, Blakeston, Philadelphia, 1949, XIV+327 p.

[47] Shapiro S.S., Wilk M.B., An analysis of variance test for normality (complete samples), Biometrika 52 (1965) 591-611.

[48] Sinclair M., Sinclair A., Iles T.D., Growth and maturation of southwest Nova Scotia Atlantic herring (Clupea harengus harengus), Can. J. Fish. Aquat. Sci. 39 (1982) 288-295.

[49] Stearns S.C., The Evolution of Life Histories, Oxford University Press, Oxford, 1992, 250 p.

[50] Sverdrup H.U., On conditions for the vernal blooming of phytoplankton, J. Cons. Int. Explor. Mer 18 (1953) 287-295.

[51] Tanasichuk R.W., Influence of biomass and ocean climate on the growth of Pacific herring (Clupea pallasi) from the southwest coast of Vancouver Island, Can. J. Fish. Aquat. Sci. 54 (1997) 2782-2788.

[52] Thompson W.F., Bell F.H., Biological statistics of the Pacific halibut fishery (2); Effect of changes in intensity upon total yield and yield per unit of gear, Report of the International fisheries (Pacific halibut) commission 2, $1934,49 \mathrm{p}$.

[53] Toresen R., Long-term changes in growth of Norwegian spring-spawning herring, J. Cons. Int. Explor. Mer 47 (1990) 48-56.

[54] Ursin E., Principles of growth in fishes, in: Miller P.J. (Ed.) Fish Phenology: Anabolic Adaptiveness in Teleosts, Symposia of the Zoological Society of London, vol. 44, Academic Press, London, 1979, pp. 63-87.

[55] von Bertalanffy L., Untersuchungen über die Gesetzlichkeit des Wachtums. I. Allgemeine Grundlagen der Theorie, mathematische und physiologische Gesetzlichkeiten des Wachstums bei Wassertieren, Wilhelm Roux. Arch. EntwMech. 131 (1934) 613-652.

[56] Walters C.J., Post J.R., Density-dependent growth and competitive asymmetries in size-structured fish populations: a theoretical model and recommendations for field experiments, Trans. Am. Fish. Soc. 122 (1993) 34-45.

[57] Ware D.M., Bioenergetics of stock and recruitment, Can. J. Fish. Aquat. Sci. 37 (1980) 1012-1024.

[58] Weatherley A.H., Gill H.S., The Biology of Fish Growth, Academic Press, London, 1987, 443 p.

[59] Winters G.H., Wheeler J.P., Length-specific weight as a measure of growth success of adult Atlantic herring (Clupea harengus), Can. J. Fish. Aquat. Sci. 51 (1994) 1169-1179.

[60] Woodruff S.D., Slutz R.J., Jenne R.L., Steurer P.M., A comprehensive ocean-atmosphere data set, Bull. Am. Meteor. Soc. 68 (1987) 1239-1250.

[61] Wyszynski M., Changes in the growth rate of southern Baltic herring in relation to hydrographic conditions and stock density in 1981-1990, ICES C.M./J 6 (1991) 16. 